\title{
Dominant Influence of Linguistic Knowledge in EFL Reading Comprehension: Schemata Analysis
}

\author{
Radiah Hamid ${ }^{1, *}$, M. L. Manda ${ }^{2}$, Abdul Hakim Yassi², Ria Rosdiana Jubhari² \\ ${ }^{1}$ Department of English Education, Faculty of Teacher Training and Education, Muhammadiyah University of Makassar, Indonesia \\ ${ }^{2}$ Department of Linguistics, Postgraduate Program of Faculty of Culture Science, Hasanuddin University, Indonesia
}

Received August 31, 2020; Revised October 19, 2020; Accepted November 11, 2020

\begin{abstract}
Cite This Paper in the following Citation Styles
(a): [1] Radiah Hamid, M.L. Manda, Abdul Hakim Yassi, Ria Rosdiana Jubhari, "Dominant Influence of Linguistic Knowledge in EFL Reading Comprehension: Schemata Analysis," Universal Journal of Educational Research, Vol. 8, No. 12, pp. 6715 - 6721, 2020. DOI: 10.13189/ujer.2020.081236.
\end{abstract}

(b): Radiah Hamid, M.L. Manda, Abdul Hakim Yassi, Ria Rosdiana Jubhari (2020). Dominant Influence of Linguistic Knowledge in EFL Reading Comprehension: Schemata Analysis. Universal Journal of Educational Research, 8(12), 6715 - 6721. DOI: 10.13189/ujer.2020.081236.

Copyright $\odot 2020$ by authors, all rights reserved. Authors agree that this article remains permanently open access under the terms of the Creative Commons Attribution License 4.0 International License

\begin{abstract}
Many studies imply that EFL students broadly use their schemata or background knowledge in comprehending the reading texts, including their formal and content schemata. Therefore, this study aims to know the influence of these schemata especially the formal schemata, grammatical and vocabulary knowledge, in reading comprehension and further determine the dominant influence between grammatical and vocabulary knowledge. Samples of 40 EFL sixth semester students of Makassar Muhammadiyah University were selected by using the Simple Random Sampling Technique. The researcher obtained the data through proficiency tests of grammar and vocabulary and reading comprehension tests. The use of regression and correlation analysis is to analyze the collected data. The results indicated that the students' grammatical and vocabulary knowledge influence their reading comprehension significantly. Moreover, their grammatical schemata are more dominant than their vocabulary knowledge, showing the new aspect of this study from the latest research, i.e., the study of [6]. The result described that the schemata about grammar play a significant role in the EFL students' comprehension processing. The correlation analysis showed that the better grammatical competence students have, the better comprehension they do. Their understanding depended more on their competence about tenses (syntactic knowledge) than on their vocabulary knowledge. The contribution of this study is to give a new perspective about grammar and vocabulary schema in the EFL students using as cognitive structures in understanding English reading
\end{abstract}

texts. It may also support developing a method that helps students use their linguistic knowledge to activate their background knowledge appropriately in understanding the different English reading texts.

Keywords Grammatical Knowledge, Vocabulary Knowledge, EFL Students, Reading Comprehension, Formal Schemata

\section{Introduction}

Recently, Choi \& Zhang (2016) conducted systematic reviews studies aimed at synthesizing the findings in the literature on the relative contribution of two types of linguistic knowledge (i.e., vocabulary and grammar) to comprehension of $\mathrm{L} 2$ reading. It discussed possible factors that may have led to the complexity and paradox of the research findings. The outcome of this analysis showed that both types of linguistic knowledge are necessary to support the understanding of L2 comprehension. Still, there was no substantial evidence to support which form of linguistic expertise more than the other. Based on the result, this study focused on finding out the dominant knowledge between grammatical and vocabulary in influencing the EFL students' reading comprehension.

Some studies investigated explicitly about grammatical and vocabulary knowledge from formal schemata views, such as [10], [20], [17], [18], and [14], such researches 
explored the relationship between knowledge of vocabulary and understanding of reading. They also usually found that vocabulary awareness plays a significant role in the comprehension of EFL reading. Ref [10] concluded that for EFL learners to understand academic texts, 98 percent of vocabulary coverage is required. In the meantime, [18] suggested that EFL learners with a broad vocabulary size should have more excellent knowledge of the words to understand the text better.

The researches, which studied linguistic knowledge including grammatical and vocabulary knowledge, are [3], [1], [15], [7], and [6]. These studies explored the contribution of grammar and vocabulary knowledge to the reading comprehension of EFL learners. Both involve cognitive strategies of students in comprehending, mainly in lexical and text-structure knowledge. Concerning this argument, [3] found that the learners' lexical and grammatical literacy is a significant factor in separating bad from skilled readers. Besides, [1] found that EFL learners encountered difficulties in interpreting the texts because they had inadequate knowledge of text-structure, meaning-building and fluent comprehension. Of the 19 studies analyzed, eight assigned more significant weight to vocabulary knowledge in [6] research, eight research studies assigned grammatical knowledge and the remaining gave mixed results. Then, eight studies found vocabulary knowledge that correlated more greatly with reading comprehension than grammatical knowledge, generally were conducted in university learners, meanwhile eight studies which found grammatical knowledge strongly correlated with reading comprehension than vocabulary knowledge, commonly were held in undergraduate learners. Therefore, this analysis concluded that both types of linguistic knowledge are significant predictors of EFL reading comprehension. However, there was no substantial evidence to support which form of linguistic knowledge contributes more than the other.

Schemata or background information is triggered in the cognitive framework by activating key terms or phrases in the text or meaning during the reading comprehension process (Cook, 1989 as cited in [13]). In line with Cook, [5] states that EFL students learn to take full advantage of their cognitive abilities to comprehend the text. The greater a reader's background knowledge of a text, the better the reader can understand the text [24]. She adds that the apparent reading difficulties of certain readers may be an issue of inadequate background knowledge or schemas. Schemas refer to the current ideas capturing specific knowledge presented in the text read; the schema has also been defined as cognitive constructs that enable the stored data in long-term memory (Ausubel, 1963 as cited in [13]).

Ref [4] suggests that an implicit mental system or schema that explains general knowledge of the universe. He describes a schema as the context knowledge stored in the human mind for reading a text; this scheme consists of various kinds of information, such as terminology information, vocabulary information, and information, allowing a reader to make inferences. Each text element is processed to an absolute minimum level and then evaluated for significance and extra attention is devoted to elements that surpass a significant criterion because of the obtained extra attention. Important text elements are better understood; since they are better learned, these text elements are often better remembered [2]. [19] points out that, in many ways, the schema affects understanding. It involves the recall of information and the storing of information; it shuts out irrelevant information and adjusts the memory after reading. To infer implicit information, the readers use text clues and the knowledge stored in their schema.

[12]:141 notes that the reader brings to bear on a text two different schema or background knowledge types. The first category is the content schema that applies to the field of content and cultural awareness. The second type of schema is the formal schema that reflects the reader's context knowledge of using syntax to organize text, coherent relationships, and rhetorical arrangement of different text types. The focus of this study is to analyze formal schemas. Knowledge of formal schema plays a central role in successful reading of the first and second languages. Standard ideas of how grammar works, what makes a coherent text, and how to organize the text have a substantial impact on how every reader attempts to process text. Mastering the text processing is needed by the second language readers at some threshold yet to be determined. However, it is evident that the greater the reader's mastery, the stronger he or she would be. Furthermore, it appears that there is support for the view that students of the first language as well as of the second language can be taught formal schematic concepts of text structure and can use that knowledge to recall and understand the text.

The schema or background knowledge about language, especially grammatical knowledge, is a fundamental understanding in the readers' cognitive processing. This knowledge helps understand the unknown words in reading text and it influences mostly in reading comprehension. Paribakht (2004), as quoted in [22], mentions that grammar awareness can assist learners in their lexical processing of L2 and subsequent acquisition of vocabulary. Concurrent with the view, grammatical knowledge influences the inference; he also notes that lexical inference makes it possible to guess the meaning of a word by combining all available linguistic signs with the learners' general world knowledge, context awareness, and relevant linguistic knowledge. Besides, Kim and Cho (2013), as cited in [6], found that, in terms of syntactic understanding, grammar competence was significantly more predictive of English reading comprehension than vocabulary information. Therefore, grammar knowledge has a comparable influence on the performance of L2 with that of vocabulary knowledge. 
Knowing the meaning of words can be difficult for second/foreign language readers. Vocabulary thus seems to be an important factor for understanding reading [23]. EFL teachers prefer to concentrate on teaching vocabulary rather than syntax, based on the assumption that a significant amount of vocabulary is required to comprehend texts. While people assume that vocabulary plays an essential role in the entire learning cycle, vocabulary is not the only factor influencing the reading of learners. Indeed, good reading comprehension is heavily dependent on the readers' awareness of the meanings of individual words that appear in a text. Vocabulary awareness has long been recognized as having a similar, albeit complex, relationship with the development of reading comprehension skills [9]. Vocabulary knowledge is not a single-face construct but includes size (or breadth, i.e., how much) and depth (i.e. how well) dimensions.

On the other hand, [8] also states that its understanding may be influenced by the degrees of syntactic knowledge that second language learners have. Learners who lack syntactic ability cannot achieve a higher level of the reading process. Also, readers need syntactic knowledge of L2 to incorporate their context information and sense of words (Koda (2005), as quoted in [25]). For example, when a person reads articles or newspapers in an unfamiliar language to verify his / her context knowledge and predict the content, he / she needs to know vocabulary of the text and its grammatical structure. Grammatical awareness is necessary for the understanding of texts, since consistency building is essential, as is word integration, to establish propositional definitions that create and integrate text models [16]. A lack of clear grammatical information also tends to compensate for deficiencies in the testing of reading comprehension.

To the extent that the texts are well written, they follow a structure familiarity for the reader. Their syntax, style, clarity of presentation, and coherence reach an acceptable level in the reader's mother language and enhance understanding. Such texts were reader-friendly or reader-considerate (Anderson \& Armbruster, 1984, as quoted in [21]:657-679). Learning may also be affected by the degree to which the reader's previous experience overlaps with the text's content. In other words, learners enable their linguistic and context information to decipher the written text or understand it. The more knowledge learners have, the more critical the comprehension abilities in EFL reading context. In this case, present research describes the important roles of the schemata as background knowledge in reading comprehension process. Thus, it can give thoughtful consideration in preparing various reading texts of standardized reading comprehension tests.

\section{Method}

Under correlation research, 40 EFL sixth semester students of Makassar Muhammadiyah University who selected by Simple Random Sampling Technique were respondents of this study. They were perceived to have equal competence in English grammar and vocabulary since they had finished all reading classes: Reading I, II, III and IV, Extensive Reading 1 and 2, and the subjects which were programmed to have completed all English skill courses. By this mind, the respondents assuming to have advanced mastery of English language components, and as readers, they were supposed to have been beyond advanced level.

The instruments are proficiency tests (grammar and vocabulary tests) and reading comprehension tests. The respondents were invited to do the tests comfortably for three hours. There were twenty-five of multiple-choice tests for grammatical proficiency tests and fifty for vocabulary tests. Knowledge of English grammar included parts of speech \& tenses, and vocabularies had vocabulary size \& word association knowledge (form, meaning \& use). There were three reading passages and three achieved levels of comprehension: literal, inferential, and evaluation comprehension (Barret's Taxonomy). The proficiency tests and the reading comprehension questions were performed in multiple choice test by a score ranging from 1 to 100 points.

Regression and correlation analysis was to analyze the collected data. There were three variables. Grammatical knowledge $\left(\mathrm{X}_{1}\right)$ and vocabulary knowledge $\left(\mathrm{X}_{2}\right)$ were independent, while reading comprehension $(\mathrm{Y})$ is the dependent variable. The data collected were analyzed by correlation analysis to determine the correlation between $\mathrm{X}_{1}$ and $\mathrm{Y} ; \mathrm{X}_{2}$ and $\mathrm{Y} ; \mathrm{X}_{1}$ and $\mathrm{X}_{2}$. Regression analysis examined the significant influence between the two independent variables (vocabulary and grammatical knowledge) and the dependent variable (reading comprehension), $\mathrm{X}_{1}$ together with $\mathrm{X}_{2}$ toward $\mathrm{Y}$. The analysis is due the research hypothesis; namely, there is a dominant influence of grammatical knowledge or vocabulary knowledge in EFL reading comprehension.

\section{Results}

\section{Regression Results}

The influence between EFL readers' grammatical and vocabulary knowledge toward their reading comprehension is presented as the results of the testing hypothesis as follows: 
Table 1. Regression Analysis

\begin{tabular}{|c|c|c|c|c|c|c|c|}
\hline \multirow{2}{*}{ HIP } & \multirow{2}{*}{$\begin{array}{c}\text { Independent } \\
\text { Variable }\end{array}$} & Dependent Variable & \multicolumn{4}{|c|}{ Direct Effect } \\
\cline { 4 - 8 } & Vocabulary & $\begin{array}{c}\text { Reading } \\
\text { Comprehension }\end{array}$ & 0.372 & 0.344 & 2.229 & 0.032 & Significant \\
\hline & Grammatical & $\begin{array}{c}\text { Reading } \\
\text { Comprehension }\end{array}$ & 0.340 & 0.376 & 2.436 & 0.020 & Significant \\
\hline
\end{tabular}

These regression results showed that both formal knowledge, vocabulary and grammatical significantly influence the students' reading comprehension. It means that the better students' grammatical and vocabulary knowledge, the better their reading comprehension. The results also showed that grammatical knowledge has dominantly influenced the students' reading comprehension by coefficient value 0.376 ; it is higher than the coefficient value of vocabulary knowledge 0.344 .

Statistically, these findings can be generalized to all students of the English Education Department of Teacher Training \& Education Faculty Muhammadiyah University of Makassar by $\mathrm{F}$ test is significant value $0.00<0.05$. By $\mathrm{R}$ square is 0.409 , it means that the research model showed the condition on the research subject with value $40.9 \%$ and the residual as $59.1 \%$ is the restriction of the research instrument as well the facts about out of researcher's capability, or something others those are not included as indicators of the variables. These residuals were unable to be predicted by the researcher and be complementary in the next discussion section. Those residuals include students' language and knowledgeability. Those aspects are not included as indicators of the variables such as text structure and morphology; the limitations of the instruments such as the questionnaire about interesting topics of reading; and the students' conditions were fasting during data collection.

\section{Correlation Results}

To know what extent the relationship among variables, the Pearson Correlation was used to analyze their significant influence on each other, as presented below.

Table 2. Pearson Correlation Analysis

\begin{tabular}{|c|c|c|c|}
\hline \multicolumn{1}{|c|}{} & Vocabulary & Grammatical \\
\hline \multirow{4}{*}{ Vocabulary } & Pearson Correlation & 1 & $.575^{* *}$ \\
\cline { 2 - 4 } & Sig. (2-tailed) & & .000 \\
\cline { 2 - 4 } & $\mathrm{N}$ & 40 & 40 \\
\hline \multirow{4}{*}{ Grammatical } & Pearson Correlation & $.575^{* *}$ & 1 \\
\cline { 2 - 4 } & Sig. (2-tailed) & .000 & \\
\cline { 2 - 4 } & $\mathrm{N}$ & 40 & 40 \\
\hline \multirow{3}{*}{$\begin{array}{c}\text { Reading } \\
\text { Comprehension }\end{array}$} & Pearson Correlation & $.561^{* *}$ & $.574^{* *}$ \\
\cline { 2 - 4 } & Sig. (2-tailed) & .000 & .000 \\
\cline { 2 - 4 } & $\mathrm{N}$ & 40 & 40 \\
\hline
\end{tabular}

The results showed the strong correlation between vocabulary knowledge and grammatical knowledge, vocabulary knowledge and reading comprehension, and grammatical knowledge and reading comprehension. These results described that if the EFL readers have good grammatical and vocabulary knowledge, they will comprehend the reading texts properly. Conversely, if they have bad or less grammatical and vocabulary knowledge, they will not understand the reading texts properly.

\section{Discussion}

The EFL student acquires their linguistic competence by learning; thus, it is in the sense when they comprehend the text, they use greater their linguistic competence in terms of grammatical and vocabulary knowledge. For example, Indonesian as the students' first language is different from English as a foreign language, especially in syntax and phonology. Like [9] states, when two languages are linguistically more distinct, there is a greater possibility of more linguistic intervention in the production.

The review study of [6], which synthesized nineteen studies on the relationship between vocabulary and grammar knowledge with comprehension of second language reading and their relative significance, also found that both types of linguistic knowledge are important underpinners of understanding of $\mathrm{L} 2$ reading, but there was no clear evidence supporting what linguistic kind of knowledge. Their result is consistent with [11]; he notes that by increasing their vocabulary and having greater control over complex syntactic structures, EFL readers can improve reading comprehension. Contemporary perspectives conclude that grammar inherently promotes learning and its presentations to the learners about the meaning of language types in text. In contrast, the present study results replied that the students use grammatical knowledge dominantly, or their grammatical knowledge is more contributory than their vocabulary.

The findings described that the students had low competence in grammatical and vocabulary, and the grammatical competence had a lower value significantly. These factual pieces of evidence were pictured in their basic competence about syntactic structures, including tenses and parts of speech, as could be seen in question and students' answers for grammatical proficiency test as follows: 
question number 2 (only three students gave the right answer for point $\boldsymbol{a}$ )

You are the only person ............. I can talk.
a. to whom
b. with who
c. that
d. which

This sentence completion was to know the students' knowledge about conjunction for object and the students had poor knowledge about this word form. Most students answered for point $b$ and $c$. This poor competence influenced the students' inferring the meaning in comprehending the reading text as described as follows:

Today, Makassar has become a modern city, boasting an array of top star-rated hotels along the coastal boulevard. But walk into a side street and you may well think you are back in the $19^{\text {th }}$ century. To get you on your way to sightsee around Makassar, here are a number of must-see landmarks.

(Quoted from Reading Passage 2, Fascinating Things to See and Do when in Makassar)

The inferential comprehension question from this passage as follows:

"Makassar has become a modern city, boasting an array of top star-rated hotels along the costal boulevard, but walk into a side street and you may well think you are back in the $19^{\text {th }}$ century". Which words show the opposite of the modern city:

\section{a. Boasting an array \\ b. A side street \\ c. But walk into \\ d. Along the coastal boulevard}

Seven students gave the right answer for $c$ (but walk into); they have lack knowledge about the conjunction 'but'. They failed to infer using of the conjunction 'but' making the sentence opposite from the prior sentence.

The students also lack the ability to understand the using of perfect tense as seen as follows :

Quoted from Reading Passage 1: Prayer as a Pillar of Islam:

"Having proclaimed syahadat wholeheartedly that there is no god but Allah and Muhammad is the Messenger of Allah, a Muslim should offer prayer (shalat) five times each day."

The literal comprehension question from this sentence as follows:

The question number 6 :

Which of the following best expresses the main idea of the passage?

a. Doing prayer five times each day is preceded by saying syahadat wholeheartedly

b. Saying syahadat wholeheartedly is preceded by doing prayer five times each day

c. The first pillar of Islam is to do pray five times a day d. The first pillar of Islam is saying syahadat wholeheartedly

Seventeen students chose ' $\mathbf{b}$ ', and only eleven students chose ' $a$ ' the right answer. The answer $b$ indicates that they have no sufficient background knowledge about grammatical ('having proclaimed') and vocabulary ('preceded'). Whereas they have good background knowledge about the Pillar of Islam, they generally know well that the first pillar of Islam is proclaiming the syahadat and the second is doing prayer five times a day. It means that they also know well that before doing prayer, the muslim must saying syahadat. For this reason, they fail to activate and interact their grammatical and vocabulary knowledge with their background knowledge about the Pillar of Islam.The students' comprehension above have significantly correlated with their competence about grammatical and vocabulary since they also lacked knowledge in proficiency tests.

Some EFL studies describe that for EFL students, the linguistic knowledge (vocabulary and grammar knowledge) is the most important knowledge which leads to a good reader. As the importance of schemata or background knowledge in EFL reading comprehension, Cook (1989), as cited in [5] states that the students must stimulate the keywords or phrase in the text or context during the reading comprehension process, so this cognitive process could be able to give full advantage in comprehending process. Therefore, the greater the background knowledge a reader has of a text, the better the reader will understand that text [24]. She adds that some readers' apparent reading problems may be insufficient background knowledge or schemata.

It can be concluded from these results that the students have insufficient background knowledge about linguistic knowledge in comprehending the reading texts. Therefore, they could not maximize their ability to infer the meaning of the reading texts. They lack linguistic knowledge as formal schemata stored in their minds for reading a text, such as information about vocabulary, tenses, or pieces of informations which enable them to make inferences. Ref [19] points out that, in many ways, the schema affects understanding. It influences recalling information as well as storing data. After reading, it shuts off irrelevant information and alters the recall. The readers use text hints and their schematic knowledge to infer implicit details. In this study, the EFL students' comprehension mostly depends on their lack linguistic knowledge, so their reading comprehension could not get the suggested meaning inferring about the text.

The linguistic knowledge, as formal schemata in readers' cognitive structure, plays a fundamental role in foreign language reading performance. Moreover, [8] notes that it seems that students who lack syntactic capacity are not able to achieve a higher level reading process, although the degrees of ESL/EFL readers' syntactic competence greatly influence their comprehension. Standard ideas of how 
grammar works, what makes a coherent text and how to organize the text have a substantial impact on how every reader attempts to process text. The readers of ESL / EFL need to master these aspects of text processing at certain thresholds, which have yet to be determined. And it's obvious the more expertise the reader has, the happier he or she will be.

Paribakht strengthened this concluding statement as cited in [22]. he mentions that grammar knowledge will assist learners in their L2 lexical processing and subsequent vocabulary acquisition. Grammar knowledge influences inferencing by including hypothesis information on word meaning with all available linguistic indications, and combining them with the general understanding of learners' world. Furthermore, in terms of syntactic awareness, grammatical knowledge was relatively more predictive of English reading comprehension than was vocabulary knowledge. This shows that grammatical knowledge have more comparable effect on EFL readers' comprehension than vocabulary knowledge. Suppose this schema exists and it captures the detailed pieces of information in cognitive structures, it will allow the information stored in long-term memory, as Ausubel stated. The schema or background knowledge about language, especially grammatical knowledge is one of fundamental knowledge that must be in cognitive processing of the readers. This knowledge is useful in understanding the unknown words in reading text and mostly influence in reading comprehension.

\section{Conclusion}

This study aims to know the influence of linguistic knowledge in EFL reading comprehension, in terms of grammatical and vocabulary knowledge, and further determine the dominant influence between grammatical and vocabulary knowledge. After analyzing the results of this study, it concludes that both grammatical and vocabulary knowledge are unbeatable in influencing the EFL students' reading comprehension. Both knowledge play significant role in inferring the meaning of the sentence which build the reading passage. Indeed, the linguistic knowledge, as formal schemata in readers' cognitive structure, plays a fundamental role in foreign language reading performance. The greater schemata that the students stimulate during reading comprehension process are the keywords or phrases in the text or context as the beginning of the cognitive function.

This study also concluded that grammatical knowledge influences more dominantly than vocabulary knowledge because the students depend on their syntactic knowledge in inferring the meaning of the sentence. Through syntactic knowledge, they could guess pieces of information about the meaning of the words and then combine them with their background knowledge. Therefore, it implies that grammatical knowledge has a more comparable effect on EFL readers' comprehension than vocabulary knowledge. Furthermore, linguistic knowledge, especially grammatical knowledge, can exist in long-term memory. It will be recalled whenever needed in text processing by EFL readers to comprehend the difficult words. In this study, EFL readers could predict more words meaning by their grammatical knowledge than their vocabulary knowledge.

This study also implies that a lot of knowledge about grammar and vocabulary should be learned and taught to the EFL students using cognitive structures in understanding English reading texts. Developing a method or strategy that supports students' ability to use and activate their linguistic knowledge is recommended to activate their background knowledge appropriately in understanding the different English reading texts. It is expected that EFL students will use a vast repertoire of language skills to gain meaning from text by building a text-based model and use their background knowledge to build a model of understanding related to the text passage situation.

\section{Acknowledgments}

I would like to give the most profound and sincere appreciation to my lovely husband for his generous assistance and encouragement. I am heavily indebted to my advisors committee: Prof.Dr.M.L. Manda, M.A.,M.Phil., Prof.Dr.HakimYassi, Dipl.TESL,M.A. and Dra. Ria Rosdiana Jubhari, M.A.,Ph.D. for their expert bits of advice, encouragement, and invaluable insightful comments.

\section{REFERENCES}

[1] Albashtawi, Abeer H., Paramaswari, J. \& Manjet, S. (2016). Linguistic Knowledge Aspects in Academic Reading: Challenges and Deployed Strategies by English-Major Undergraduates at a Jordanian Institution of Higher Education. Higher Education Studies; Vol. 6, No.3;2016ISSN1925-4741 E-ISSN 1925-475X Published by Canadian Center of Science and Education, , doi:10.5539/hes.v6n3p61,URL: http://dx.doi.org/10.5539/hes.v6n3p61

[2] Anderson, R. C. \& P.D. Pearson. (1984) A Schema-Theoretic View of Basic Processes in Reading Comprehension in Handbook of Reading Research. NY : Longman Inc. p.255-291.

[3] Aryadoust, V. \& Baghaei, Purya. (2016). Does EFL Readers' Lexical and Grammatical Knowledge Predict Their Reading Ability? Insights from a Perceptron Artificial Neural Network Study. Educational Assessment, 21:2, 135-156, http://dx.doi.org/10.1080/10627197.2016.1166343

[4] Bartlett, F.C. (1932). Remembering: A Study in Experimental and Social Psychology. London: CUP. 
[5] Birch, B.M. (2015). English L2 Reading.Getting to the Bottom. Third Edition. NY : RT \& F Group.

[6] Choi, Y. \& D. Zhang. (2017). The Relative Role of Vocabulary and Grammatical Knowledge in L2 Reading Comprehension: a Systematic Review of Literature", International Review of Applied Linguistics in Language Teaching, June 2018, DOI: 10.1515/iral-2017-0033, https://www.researchgate.net/publication/326032322

[7] Eunjou Oh. (2015). Comparative Studies on the Roles of Linguistic Knowledge and Sentence Processing Speed in L2 Listening and Reading Comprehension in an EFL Tertiary Setting”, Reading Psychology. http://dx.doi.org/10.1080/02 702711.2015.1049389

[8] Grabe, W. (1991). Current Developments in Second Language Reading Research". TESOL Quarterly.25(3): 375-406. 1991.

[9] Grabe, W. (2009). Reading in a Second Language: Moving from Theory to Practice. NY : CUP.

[10] Güngör, F., \&Yayl1, D. (2016). The Interplay between Text-based Vocabulary Size and Reading Comprehension of Turkish EFL Learners. Educational Sciences: Theory \& Practice, 16, 1171-1188, 2016.

[11] Hedge, Tricia. (2003). Teaching \& Learning in the Language Classroom. UK : OUP.

[12] Hudson, Thom. (2007). Teaching Second Language Reading. NY : OUP.

[13] Imran, Nasmilah. (2005). Classroom Instruction, Schema Related Actors, and Individual Differences in Adult EFL Reading Performance. A Dissertation of Doctor of Philosophy, University of Newcastle, Australia.

[14] Jamalipour, S. \& A.A.K. Farahani. (2015). The Effect of Vocabulary Knowledge and Background Knowledge on Iranian EFL Learners' L2 Reading Comprehension. Journal of Applied Linguistics and Language Research Volume 2, Issue 2, pp. 107-121, 2015, Available online at www.jallr.ir ISSN: 2376-760X.

[15] Joh, Jeongsoon \& Plakans, Lia. (2017). Working Memory in L2 Reading Comprehension: The Influence of Prior Knowledge. www.elsevier.com/locate/system
[16] Kintsch, W. (1998). Comprehension: A Pardigm for Cognition. Cambridge : CUP.

[17] Ma,Yu-han and Wen-ying Lin. (2015). A Study on the Relationship between English Reading Comprehension and English Vocabulary Knowledge", Hindawi Publishing Corporation Education Research International, Volume 2015, Article ID 209154, 14 pages http://dx.doi.org/10.115 $5 / 2015 / 209154$

[18] Mohammad Mohammadi, Seyed \& Bayat Afshar, Nasrollah. (2016). Vocabulary Knowledge Lerning and Reading Comprehension Performance: Which Oneis Superior-Bread thor Depth", International Journal for $21^{\text {st }}$ Century Education, Vol. 3.2. (pp 5-14), ISSN: 2444-3921, 2016.

[19] Murray. (1980). The Effect of Two Techniques which Elicit Productive Response on the Comprehension of Content Area Reading Materials. Unpublished MA Dissertation, The University of Connecticut.

[20] Perfetti, C. and J. Stafura. (2014). Word Knowledge in a Theory of Reading Comprehension. Scientific Studies of Reading", 18:22-37, 2014 Copyright (C) 2014 Society for the Scientific Study of Reading. ISSN: 1088-8438 print/1532-799 X online.

[21] Pearson, P.D. (1984). Handbook of Reading Research. NY : Longman Inc.

[22] Rajnbar, M. (2012). The Relationship between Grammatical Knowledge and the Ability to Guess Word Meaning: The Case of Iranian EFL Learners with Upper Intermediate Level of Proficiency", Theory and Practice in Language Studies, Vol. 2, No. 6, pp. 1305-1315, June 2012@2012 ACADEMY PUBLISHER Manufactured in Finland. doi:10.4304/tpls.2.6.1305-1315. ISSN 1799-2591

[23] Richard, J.C, and T.S. Rodgers. (1986). Approaches and Methods in Language Teaching: A Description and Analysis. Cambridge: CUP.

[24] Stevens, K.C. (1980). The Effect of Background Knowledge on the Reading Comprehension of Ninth Graders. Journal of Reading Behavior, Vol. XII, No. 2, 1980.

[25] Yu Chen, K. (2011). The Impact of EFL Students' Vocabulary Breadth of Knowledge on Literal Reading Comprehension. April 2011 Asian EFL Journal Volume 51. 